\title{
PROJETO REGENERATIVO: UMA VISÃO HOLÍSTICA DE PLANEJAMENTO PARA A INTERDEPENDÊNCIA DO CAMPUS COM A CIDADE
}

\author{
FÁBIO PEDROSO DIAS, M.SC. UFSC \\ JOSÉ RIPPER KÓS, PhD. | UFSC
}

Através das transformações na evolução das Instituições de Ensino Superior (IES), percebemos uma mudança que desafia o desenvolvimento em concomitância com a conservação dos ecossistemas. O sistema atual, fundamentado no desenvolvimento intensifica a crise ecológica. Surge, neste contexto, o projeto regenerativo - uma metodologia que propõe que os ambientes construídos podem produzir mais energia e recursos do que consomem e gerar um impacto positivo no ambiente natural e social.

O projeto regenerativo aplicado nas iniciativas de elaboração de planejamento das IES levará os profissionais a pensarem mais sobre os sistemas naturais, bem como as questões sociais, culturais e econômicas; adotando um conjunto muito mais amplo de soluções, inovações e criatividade para o ambiente construído (DALTON, HAJRASOUILHA e RIGGS, 2018).

Evidências emergentes mais recentes motivam para a necessidade de um "paradigma de sustentabilidade regenerativa" que entrelaçam os sistemas humanos em uma parceria cocriativa com a natureza; visando aplicar um conjunto de práticas de projeto e engenharia ecológica no seu desenvolvimento narrativo, modificando o ambiente urbano de acordo com as exigências à procura de soluções duradouras com uma abordagem integrada dos problemas físicos, ambientais e econômicos (DU PLESSIS, COLE, 2011).

Deste modo, o presente trabalho utilizou uma metodologia, que foi aplicada no contexto urbano do Campus Sede da Universidade Federal de Santa Catarina (UFSC), tendo como objetivo apresentar um modelo de planejamento, fundamentado na teoria do projeto regenerativo com a finalidade de reconstituir as fronteiras urbanas do campus com seus arredores, a partir da necessidade que a universidade tem de se abrir para a cidade; demonstrando como estas relações podem acontecer de uma forma diferente através da restauração dos ecossistemas juntamente com as relações humanas e como que elas se complementam.
A metodologia foi realizada em dois momentos: Primeiramente, com uma finalidade qualitativa; com a utilização das Guias de Projeto Regenerativo para Campus Universitário observou-se os problemas existentes no recorte de estudo, os quais serviram como base para a elaboração dos potencias regenerativos. No segundo momento, os potenciais regenerativos obtidos foram organizados por similaridade de assunto em 10 Tópicos; configurando assim as diretrizes para o projeto regenerativo no Campus Trindade da UFSC.

A principal premissa que a pesquisa pode apontar foi o direcionamento para a elaboração de projetos que atendam a reconstrução de ecossistemas em concomitância às necessidades humanas. Estando expresso: na restauração da paisagem; na regeneração de ecossistemas; no tratamento de águas residuais e na drenagem urbana; e, como um incentivador de atratividade de urbanidade com denotada segurança em torno dos sistemas de mobilidade.

Concluiu-se que o 10 Tópicos apresentam diretrizes que minimizam os impactos ambientalmente destrutivos ao se integrar com processos vivos e como a adaptação efetiva e integração com processos da natureza.

\section{REFERÊNCIAS}

DALTON, L. C.; HAJRASOUILHA, A. H.; RIGGS, W. W. State of the art in planning for college and university campuses: site planning and beyond. Journal of the American Planning Association, 2018, p.145-161.

DU PLESSIS, C.; COLE, R. J. Motivating change: shifting the paradigm. Building Research \& Information, 2011, p.436-449. 
